\title{
How to increase job satisfaction: the role of participative decisions and feeling trusted
}

\author{
Jacob Guinot, Adrián Monfort and Ricardo Chiva \\ Department of Business Administration and Marketing, Universitat Jaume I, \\ Castellón de la Plana, Spain
}

\begin{abstract}
Purpose - In the last few years a new management style and paradigm has emerged with the aim of improving employee motivation, commitment and satisfaction through participatory management practices and more democratic organizational structures. Based on this new paradigm, this study examines the consequences of participative decision making for job satisfaction and trust.

Design/methodology/approach - To examine the proposed relationships structural equation modelling was used on a sample of 3,364 employees conducted by the European Foundation for the Improvement of Living and Working Conditions (Eurofound).

Findings - Results confirm that participative decisions positively influence job satisfaction both directly and indirectly by means of employees' perception of trust.

Originality/value - Based on democratic management style, this study shows how participative decisions and trust can increase job satisfaction.
\end{abstract}

Keywords Employee participation, Participative decisions, Trust, Job satisfaction

Paper type Research paper

\section{Introduction}

Recent years have witnessed the emergence of a new management style based on more democratic structures, in contrast to the traditional management model of hierarchical relationships and control (Chiva, 2014; Huang et al., 2016; Kim, 2002; Laloux, 2014; Tremblay, 2012). The appearance of these democratic models can be explained by the advent of a business conscience that pursues the common good - including employee satisfaction - and understands that employees play a decisive role in the viability of the company. Indeed, research has shown that employees perform better individually when they do not have to follow specific guidelines and when they are not constantly monitored by their superiors (Benoliel and Somech, 2010; Kim, 2002; Swearingen, 2017). This has led to the expansion of a management style concerned with improving the motivation, commitment and satisfaction of employees through participatory practices embedded in democratic organizational structures (Guest, 2017; Salas-Vallina et al., 2020).

These democratic companies are distinguished by their consideration of workers not as a "stakeholder", but as a "constituent part" of the organization (Yukl and Becker, 2006). In other words, employees are recognized as trustworthy and have a high level of decision-making power. These companies apply a system of participatory corporate governance, in which employees have the capacity to influence organizational decisions and levels of control (Tannenbaum, 1968). This governance system moves away from management approaches of control and submission at work to focus on managerial trust in employees (Chiva, 2014). Hence, the presence of trust is conceived as a core component in organizations applying a participatory management (Davis, 2001; Harrington, 2017).

This work was supported by the UJI Research Programmes (UJI-B2019-04 and UJI-A2019-22). We would also like to thank Mary Savage for providing language help.
Participative decisions and feeling trusted

Received 10 October 2020 Revised 5 February 2021 22 April 2021

Accepted 22 April 2021 
The role of trust in organizations has been extensively examined in the field of organizational research. Trust is seen as an essential condition to create a healthy working environment and for employee wellbeing (Baptiste, 2008). More particularly, the organizational literature indicates that interpersonal trust increases job satisfaction (i.e. Braun et al., 2013; Guinot et al., 2014; Matzler and Renzl, 2006). Job satisfaction is one of the most studied concepts in the literature due to its benefits such as productivity, personal well-being and organizational commitment (Aziri, 2011). However, research on the linkage between trust and job satisfaction has focused particularly on a bottom-up direction (from employees to their leaders) or on a horizontal level (between team members or peers at the same level). Thus, the importance of employees feeling trust from their leaders or organizations has been neglected. In fact, our literature review reveals that little is known about the impact managers' trust in subordinates has on job satisfaction. This lack of research on the top-down direction of trust has also been noted by academics such as Brower et al. (2009) or more recently Guinot and Chiva (2019).

Moreover, recent reports have warned of the decline of trust in organizational settings. One example is the global survey conducted by Ernst and Young, which found that less than half of global professionals trust their employer, boss or team/colleagues (Twaronite, 2016). This tendency has also attracted academic attention, and several authors (e.g. Bingham, 2017; Brower et al., 2017) have found that many employees do not feel trusted by their managers. In turn, according to the 2019 Edelman Trust Barometer, it is now more important than ever for employers to listen to their employees in organizations, since $74 \%$ of employees expect to be included and have a voice in key decisions. Thus, by creating the conditions for employee participation, business leaders can help to fulfil employee expectations. Likewise, by promoting employee empowerment, business leaders may send a signal that the organization trusts its employees.

Accordingly, the objective of this article is to explore the relationships between three variables: participative decision making, managers' trust in employees and job satisfaction. Although the literature suggests some linkage between these variables, there are no empirical findings that combine these relationships. We propose that participative decision making may provide a basis on which to increase employees' perception that managers trust them, thus triggering job satisfaction, both directly and indirectly (by means of trust). In addition, this study is unusual in that it takes a different perspective on the concept of trust to that generally taken in the literature: we approach trust from the perspective of employees' perceptions that they are trusted, since there are indications that this variable may be closely related to employee participation and job satisfaction. By providing empirical evidence on these relationships, we aim to shed light on some of the triggers and consequences of this side of trust. Moreover, exploring the effects of participation at work may serve to advance knowledge about the appropriateness and relevance of democratic management systems, particularly to improve job satisfaction. To examine the proposed relationships we apply structural equation modelling (SEM) in a sample of 3,364 employees in Spain. The sample was taken from the European Working Conditions Survey of 2015, conducted by the European Foundation for the Improvement of Living and Working Conditions (Eurofound).

\section{Theoretical framework}

In the following subsections we provide a theoretical review and analyse current trends and challenges in the concepts addressed in this study: employee participation, trust and job satisfaction. 


\subsection{Employee participation}

Employee participation can be defined as a work system in which influence on decision making is shared among employees at different hierarchical levels (Wagner, 1994). It includes actions such as employees having the opportunity to suggest improvements in the way things are done, engaging in how work is organized and what is done and giving opinion about who does what (Cotton et al., 1988). Organizations oriented to participative work environment delegate large amount of control towards employees (Behravesh et al., 2020). By sharing responsibility, the exchange of information is likely to flow, and everyone participates in the resolution of problems (Wong et al., 2018). Employee participation tends to improve organizational aspects such as product and service quality and it can also reduce absenteeism; in other words, it improves organizational performance (Bhatti and Qureshi, 2007). Bhatti and Qureshi (2007) concluded that employee participation has a positive impact on three aspects: job satisfaction, employee engagement and employee productivity in the company. In turn, employees who are involved in making decisions tend to be more motivated, committed and perceive less levels of burnout (Behravesh et al., 2020). Moreover, they shown less intentions of quitting and have a greater feeling of control over their work lives (Behravesh et al., 2020; Crawford et al., 2010). Accordingly, organizations and employees can benefit from participative decision making.

Managers are now becoming increasingly aware of the relevance of involving workers in decision making. Consequently, a growing number of companies are empowering and giving freedom to their employees, as this tends to make them more productive and efficient. However, for many other firms worker participation is not given sufficient priority. According to Bhatti and Qureshi (2007), this widespread lack of interest in the human resources of organizations may be because their influence is not usually measured in economic terms. With or without such measurements, human resources managers and management in general should keep in mind the need to involve the human resources system in their strategic plans, since it is necessary not only for the company's success in the market but also for its survival.

\subsection{Trust}

A significant amount of research has addressed the role of trust in organizations, and several definitions of the concept have been put forward. However, one of the most popular and commonly used is that proposed by Mayer et al. (1995, p. 712):

... the willingness of a party to be vulnerable to the actions of another party based on the expectation that the other will perform a particular action important to the trustor, irrespective of the ability to monitor or control that other party.

Another similar definition of trust comes from Rousseau et al. (1998, p. 395), who stated that trust is the "intention to accept vulnerability based on positive expectations of the intentions or behaviour of another". In this sense, vulnerability indicates that a relationship of trust implies that something is at stake and therefore can be lost by the trusting party. Of the many terms found in the literature to refer to the two parties involved in a relationship of trust, in this article we use the "trusting party", understood as the one who trusts, and the "trusted party", understood as the one in whom the trust is deposited by the trusting party. Alternative terms are "trustor" and "trustee", respectively.

\subsection{Job satisfaction}

Job satisfaction is probably the most extensively studied form of work-related subjective well-being (Bakker and Oerlemans, 2011). One author who has explored the concept of job satisfaction in great depth is Locke, who defines it as that "pleasurable emotional state" (1969,
Participative decisions and feeling trusted 

own values. The author considers that throughout their lives people voluntarily or involuntarily configure a set of values that guide their decisions and actions. He argues that job satisfaction is nothing more than the identification of an employee's position with the values that he or she has constructed. In contrast, job dissatisfaction consists of an "unpleasurable emotional state" (Locke, 1969, p. 316) that arises because workers consider that performing their job is frustrating and limits them in the achievement of their personal values. Locke divides values into two groups: moral and specific. Taking salary as an example, the moral aspect would be the value of money and the specific aspect would be the amount that employees expect to earn at a given time in their career.

Following Locke, for an individual's values to become a determinant of job satisfaction, most of them must be rational. This is because individuals whose code of ethics contains many irrational values will end up experiencing value conflicts that make it impossible for them to be satisfied in the company. In parallel, Locke also points out that both satisfaction and dissatisfaction depend on the difference between what the employee's ideal job would be, and reality. If this difference is zero or very small, the employee feels job satisfaction. He also argues that the reasons why workers are satisfied lie in the characteristics of the job as well as those of employees themselves. Logically, another conclusion Locke reaches is that an individual's job satisfaction is due to the set of variables that make up a job, including salary, quality of supervision or work climate, among others.

Accordingly, job satisfaction is a collection of feelings and beliefs that employees have about these aspects of their job (Aziri, 2011). Hence, job satisfaction represents a feeling that job expectations match real rewards. Therefore, job satisfaction is linked to the experiences and situations surrounding the employee that affect their perception of their job (Gabriel et al., 2014; Judge et al., 2020). In other words, job satisfaction is the employee's positive affective response to their job, resulting from their comparison of actual and desired outcomes (Judge et al., 2012).

\section{Research hypotheses}

The theoretical framework presented above includes definitions of the three variables that make up the case under study, different relationships between these variables and other concepts that are part of the organizational environment. In this section we explore the relationships between the three concepts (Figure 1).

Figure 1.

Research model

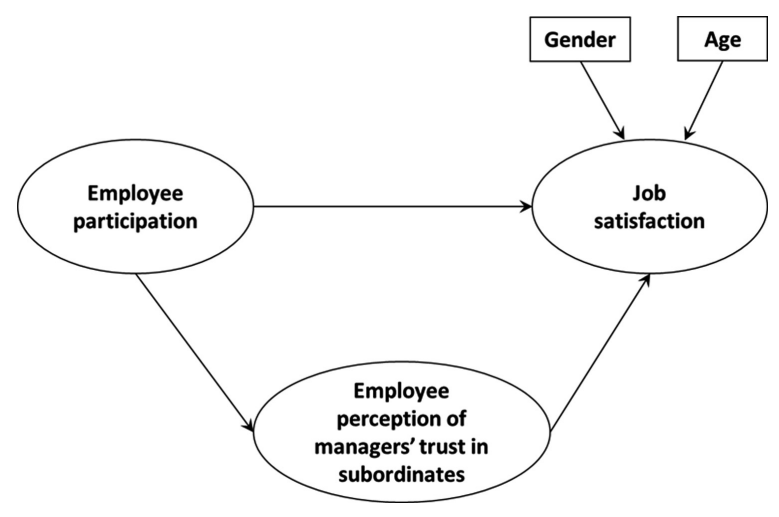




\subsection{Employee participation and job satisfaction}

The first possible relationship to be demonstrated is that between employee participation and job satisfaction, a link that has been analysed in recent decades. For example, Bhatti and Qureshi (2007) concluded that employee participation is positively linked to job satisfaction. According to Kim (2002), employee involvement in the company's strategic planning processes is positively related to workers' satisfaction. This author also argues that the effect is greater when participatory management is accompanied by effective communication monitoring. He adds that to increase job satisfaction, both private and public sectors should focus on changing their traditional hierarchical structure to a flatter, more participatory one. Employee involvement is thought to have positive consequences for job satisfaction since it increases workers' motivation, self-realization and empowerment.

It may therefore seem logical that subordinates who can participate in different areas of the company and are valued for their contributions to decision making may feel more satisfied in their job. It should be noted, however, that this assumption only makes sense if the negative implication of increased participation, such as higher job stress, is lower than the satisfaction it produces (Weinberg et al., 2010). In any case, throughout the literature some authors, such as Alas (2007) and those mentioned above, have concluded that job satisfaction and employee participation are positively correlated. Others, such as Wilkinson et al. (2010), also argue that job satisfaction, together with employee engagement, are indicators capable of measuring the success of employee participation to a certain level of precision. That is, according to these authors, employee satisfaction can be explained by the degree of participation. Hence, when workers are involved in decisions such as setting their work objectives, improving work processes, or choosing their colleagues, they obtain higher levels of satisfaction.

Considering the above, we propose the first hypothesis:

H1. There is a positive and significant relationship between employee participation and job satisfaction.

\subsection{Employee participation and employee perception of managers' trust in subordinates}

Intuitively, we might expect the variables employee participation and employee perception of managers' trust in subordinates to be positively related, so the more participation employees are allowed, the more they will perceive that their superiors trust them. In other words, it can be assumed that when subordinates are more involved in organizational decision making, they may perceive that this is because their superiors trust them. In fact, over the past decades, authors such as Wilkinson et al. (2010) have linked employee participation to trust. It seems logical to consider that when managers encourage their employees to be more participatory and provide them with tools to fully develop their capabilities, individuals will feel respected by their superiors and perceive that they trust them, thus providing a basis for the development of the cognitive side of managers' trust in subordinates.

Coyle-Shapiro et al. (2002) suggested that for individuals to perceive that their superiors trust them, and that their decisions are important and positive for the organization, managers must first encourage workers to improve their skills and knowledge. One way to do that is by encouraging employee participation. In turn, any system managers introduces to increase employee participation must be underpinned by a long-term commitment, because if workers perceive that the company is losing interest in the project, they may suspect that managers have stopped trusting them (Bruno and Jordan, 1999). In general, changes in certain aspects of organizations provide an opportunity for management to involve their subordinates in the processes of change. If superiors count on their subordinates to improve a certain aspect of the company, those lower down the hierarchy would logically feel that their superiors trust them. This may be particularly significant from the cognitive side of trust, which is based on the premise that the other party will be competent and responsible in performing his or her role.
Participative decisions and feeling trusted

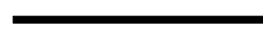


H2. There is a positive and significant relationship between employee participation and employee perception of managers' trust in subordinates.

\subsection{Employee perception of managers' trust in subordinates and job satisfaction}

The relationship between trust and employees' satisfaction in their workplace has attracted much research attention. According to Altuntas and Baykal (2010), workers tend to show a higher level of enthusiasm and happiness and, therefore, satisfaction when they perceive a climate of trust in their organization. In the same way, Matzler and Renzl (2006) found that trusting relationships between individuals and colleagues at the same level, as well as between managers and their subordinates, enhance job satisfaction. Perry and Mankin (2007) also concluded that satisfaction levels are directly related to trust levels. Additionally, trust not only directly generates satisfaction but also favours the emergence of other working conditions that lead to employee satisfaction (Dirks and Ferrin, 2001).

Trust implies a willingness to synchronize, to help and to commit to each other, which leads to reduced stress and anxiety in the workplace (Lau and Tan, 2006). In the absence of trust, a climate of uncertainty and insecurity is generated. In turn, uncertainty over long periods leads to a situation of stress and, therefore, dissatisfaction. Other triggers of job dissatisfaction may be unhealthy rivalry between employees in their drive to move up the corporate hierarchy, lack of communication, lack of support and the favouritism that managers may show towards certain employees (Beehr, 1981). If supervisors do not trust subordinates and place them under undue pressure, they will feel anxious and overwhelmed by the demands of their position and, therefore, highly dissatisfied. On the other hand, the perception of risk plays a fundamental role in job satisfaction, so a lower level of perceived risk increases job satisfaction (Guinot et al., 2014). Thus, the existence of trust in a company reduces risk perception and stress, and encourages a supportive work climate, which leads to increased levels of job satisfaction.

Based on this series of ideas, we posit our third hypothesis:

H3. There is a positive and significant relationship between employee perception of managers' trust in subordinates and job satisfaction.

\subsection{The mediating role of managers' trust in subordinates between employee participation and job satisfaction}

As we discussed in the previous hypotheses, we may find three positive effects among the variables examined: participation and job satisfaction, participation and trust and trust and job satisfaction. Thus, following the above theoretical arguments and hypothesized relationships, we propose our final hypothesis in which the effect of employee participation on job satisfaction is mediated by managers' trust in subordinates. In fact, literature suggests that trust plays a role as a social exchanger (Guinot and Chiva, 2019), so performing a mediating role between some variables and positive affective responses such job satisfaction. Based on social-exchange theory (Blau, 1964), participative decisions may be create high-quality leader-follower relationships by means of encouraging a feeling of trust in subordinates, which may cause individuals to respond by feeling good and satisfied (Lawler and Thye, 1999). Testing this more complex hypothesis of reciprocal exchange could be useful to provide a more detailed picture of the posed relationships, particularly to further explain the participation-satisfaction linkage. Thus, we present the fourth hypothesis:

H4. The relationship between employee participation and job satisfaction is mediated by employee perception of managers' trust in subordinates. 


\section{Research methodology \\ 4.1 Sample}

The data used in this research were taken from the European Working Conditions Survey of 2015, conducted by the European Foundation for the Improvement of Living and Working Conditions (Eurofound). This institution belongs to the European Union and was created by the European Council to study and improve the living and working conditions of individuals in Europe. The main objective of the survey is to quantify the conditions of workers in Europe, both for employed and self-employed persons. It also aims to analyse the relationships between different aspects of working conditions, distinguish risk groups, identify issues of concern and progress, monitor trends and contribute to European policy making. The sample used in this article only considered interviews with individuals in Spain.

At the European level, the survey was carried out in $28 \mathrm{EU}$ member states, Norway, Switzerland, Albania, the former Yugoslav Republic of Macedonia, Montenegro, Serbia and Turkey (a total of 35 countries). Although the target sample size was set at 1,000 in most countries, for nations with larger populations this figure was higher: 1,200 in Poland, 1,300 in Spain, 1,400 in Italy, 1,500 in France, 1,600 in the United Kingdom and 2,000 in Germany and Turkey. In addition, Eurofound offered countries the possibility to increase their sample size, an option taken up by Belgium, Slovenia and Spain, which increased their respondents to $2,500,1,600$ and 3,300, respectively. The final sample totalled 43,850 individuals. In the case of Spain, the total number of interviewees after the fieldwork was 3,364, which is the sample size studied to test our theoretical model. The workforce in the sample has less female $(47 \%)$ than male $(53 \%)$ representation; more than a quarter of the workers did not finish high school; it is concentrated in the 35-49 age group; three out of four workers are in the service sector (76\%); and the vast majority $(79 \%)$ work full time. The surveys were carried out between 3 March and 29 September, 2015.

\subsection{Measurement of the variables}

To measure the variables, we used some of the questions from the interviews conducted for the 2015 European Working Conditions Survey. We selected the questions that best represented a measurement of the three concepts discussed in this article: employee participation, employee perception of managers' trust in subordinates and job satisfaction.

4.2.1 Employee participation. Three items were used to evaluate employee participation. They were all measured on a scale of 1-5 (1: always, 2: usually, 3: sometimes, 4: rarely, 5: never), and included other possible answers (7: not applicable, 8: do not know, 9: no answer). The items were: "you are consulted before objectives are set for your work", "you are involved in improving the work organization or work processes of your department or organization" and "you have a say in the choice of your work colleagues". In the survey, these questions correspond to Q61C, Q61D and Q61E, respectively. Some authors, such as Kim (2002) and Guinot and Barghouti (2019), have used similar items to measure employee participation. These items essentially measure the forms of participation corresponding to direct communication and bottom-up problem solving, which implies giving an opinion in faceto-face interactions and participating in decisions that are assumed to correspond to managers.

4.2.2 Employee perception of managers' trust in subordinates. The level of employee perception of managers' trust in subordinates was measured with a single item: "the management trusts the employees to do their work well", and therefore involves the cognitive dimension of trust. A scale of 1 to 5 was used for this purpose (1: fully agree, 2: partially agree, 3: neither agree nor disagree, 4: partially disagree, 5: strongly disagree) and included other possible responses (7: not applicable, 8: do not know, 9: no answer). In the survey, this question corresponds to Q70B. Unlike the previous case, this variable is measured by a single element. It should be noted that some authors, such as Shah (1998) or Guinot et al. (2014), have
Participative decisions and feeling trusted 
measured interpersonal trust with a single item. In addition, Ganzach (1998) argues that the use of a single item to measure a certain variable is not only no less valid than the use of different items, but could even be more reliable (Wanous et al., 1997).

4.2.3 Job satisfaction. Job satisfaction was measured with the question "on the whole, are you very satisfied, satisfied, not very satisfied or not at all satisfied with working conditions in your main paid job?", using a scale from 1 to 4 (1: very satisfied, 2: satisfied, 3: not very satisfied, 4: not at all satisfied), and including other possible answers (8: do not know, 9: no answer). This question corresponds to Q88 of the European Survey on Working Conditions (2015). Therefore, as with the previous variable, job satisfaction was measured using a single item, following previous empirical research (e.g. Chiva and Alegre, 2009; Ganzach, 1998; Guinot et al., 2014; Wanous et al., 1997).

4.2.4 Control variables. The age and gender of employees were used as control variables, since they may significantly influence job satisfaction.

4.2.5 Age. According to authors such as Kalleberg and Loscocco (1983) and Bos et al. (2009), job satisfaction and age are positively and significantly related, so that the older a person is, the greater their job satisfaction.

4.2.6 Gender. Empirical studies addressing job satisfaction typically include individual control variables such as gender (Chiva and Alegre, 2009; Ganzach, 1998).

\subsection{Descriptive statistics and psychometric properties of the measurement scales}

Table 1 presents correlation factors between the study variables and Table 2 shows the descriptive statistics (mean and standard deviation) for each of the variables included in the model. The two tables were obtained using the IBM SPSS 22 program for Windows.

Note that unlike the other parameters, which are quantitative, employee gender is a qualitative variable; consequently, we assigned the values 1 to male gender and 2 to female gender. The value 1.47 in the table therefore has a symbolic meaning and does not represent an average as such, but as it is below 1.5, it indicates that slightly more men (53\%) than women $(47 \%)$ were interviewed in the National Survey on Working Conditions. The average age of those surveyed is 42.46 years, and the average data for the other variables corresponding to the sample questions are presented numerically in section 4.2. Measurement of the variables. The standard deviation measures the degree of dispersion of the data for the average values. In the case of employees' age, given that the minimum sample was set at 16 years of age and there was no age limit, the standard deviation is greater than 38 years.

Using confirmatory factor analysis, we have analysed the one dimensionality of the measurement scales of the construct employee participation. Results of the confirmatory factor analysis indicators indicate the one dimensionality of the construct employee participation ( $\phi$-value $>0.05$; RMSEA $=0.000$; BBNFI $=1.000 ; \mathrm{CFI}=0.999)$. Moreover, Cronbach's a coefficient shows a value of 0.713 . This value is above the minimum acceptable value 0.7 (Nunnally, 1978), thus confirming the reliability of the scale.

Table 1 shows the correlation factors between the parameters, using Pearson's correlation coefficient (normally designated with an $R$ ), whose function is to indicate the relationship or dependency between the two variables in a two-dimensional study. The $p$-values are also reported in Table 1 and will be compared with the established level of significance. The present model aims to show relationships between three variables, two at a time, for which the significance level 0.01 is taken as a reference. First, between the variables Employee perception of managers' trust in subordinates and Job satisfaction, given that the Pearson coefficient is 0.257 and the $p$-value is less than $0.01(0.000<0.01)$, the relationship is positive and significant. Regarding the variables Employee participation and Job satisfaction (assigned number 7 in the tables), given that the former is justified by three items, the study must be carried out for each of these cases. By way of simplification, we denote the three items belonging to the variable Employee participation with the numbers 3, 4 and 5, which are those 


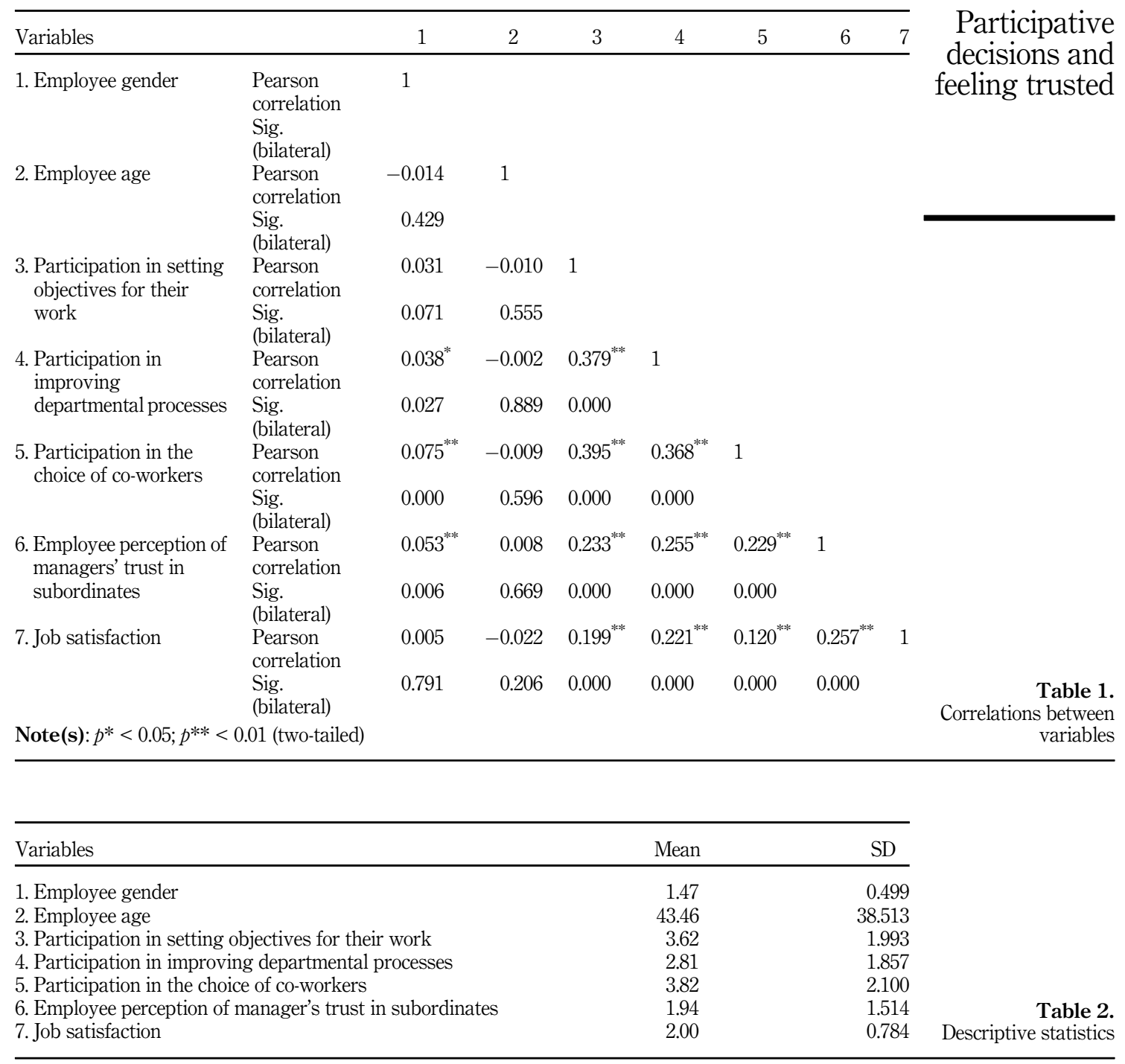

assigned in the previous tables. Between 3 and 7, the $R$ is 0.199 and the $p$-value is less than $0.01(0.000<0.01)$; between 4 and 7 , the $R$ is 0.221 and the $p$-value is less than 0.01 $(0.000<0.01)$; and between 5 and 7 , the $R$ is 0.120 and the $p$-value is less than 0.01 $(0.000<0.01)$. Thus, there is a positive and significant relation between the Employee participation and Job satisfaction parameters. Finally, the analysis of the relationship between variables Employee participation and Employee perception of managers' trust in subordinates (assigned number 6 in the tables) is very similar to the previous one: between 3 and 6 , the $R$ is 0.233 and the $p$-value is less than $0.01(0.000<0.01)$; between 4 and 6 , the $R$ is 0.255 and the $p$-value is less than $0.01(0.000<0.01)$; between 5 and 6 , the $R$ is 0.229 and the $p$-value is less than $0.01(0.000<0.01)$. 
These results indicate that the variables Employee participation, Employee perception of managers' trust in subordinates and Job satisfaction are positively and significantly related, and given that we used a significance level of 0.01 , these conclusions can be stated with $99 \%$ certainty. Similarly, the results in Table 1 show that Employee gender $(R=0.005$; $p$-value $=0.791)$ and Employee age $(R=-0.022 ; p$-value $=0.206)$ do not have a significant relationship with Job satisfaction.

\section{Analysis and results}

The statistical program EQS 6.1 for Windows and SEM were used to perform the analysis of the model. Based on the data used (Satorra-Bentler chi-square = 19.7389; degrees of freedom $=9 ; p=0.01959$; Bentler-Bonnet normed fit $=0.991$; Bentler-Bonnet non-normed fit $=0.988$; Comparative fit index: 0.995; Root mean square error of approximation $=0.023$ ), the results show an adequate model fit (Figure 2).

As shown in Figure 2, the model's regression coefficients indicate a positive relationship between Employee participation and Job satisfaction $\left(\beta_{1}=0.400 ; t=9.278 ; p<0.01\right)$, thus confirming H1. The results also show a positive relationship between Employee participation and Employee perception of managers' trust in subordinates $\left(\beta_{2}=0.381 ; t=10.070 ; p<0.01\right)$, which supports H2. Finally, Employee perception of managers' trust in subordinates has a positive effect on Job satisfaction $\left(\beta_{3}=0.536 ; t=8.573 ; p<0.01\right)$, supporting H3. All three hypotheses proposed in the model are therefore confirmed. This regression analysis complements the results of the previous section in that it provides some causality between the variables, since previously we had only shown that they were positively and significantly correlated.

We then analysed the mediating effect of the variable Employee perception of managers' trust in subordinates on the relationship between Employee participation and Job satisfaction, drawing on the procedures used by Tippins and Sohi (2003). For this purpose, a comparison is made between the mediation model (which includes the mediating variable) and a direct effects model (which strictly relates Employee participation to Job satisfaction). The comparison of the two systems shows whether or not the differences between them are significant. In order to conclude that the mediating model is more in line with reality than the direct effects model, four conditions must be met (Tippins and Sohi, 2003): (1) the mediation

Figure 2. Results of the research model

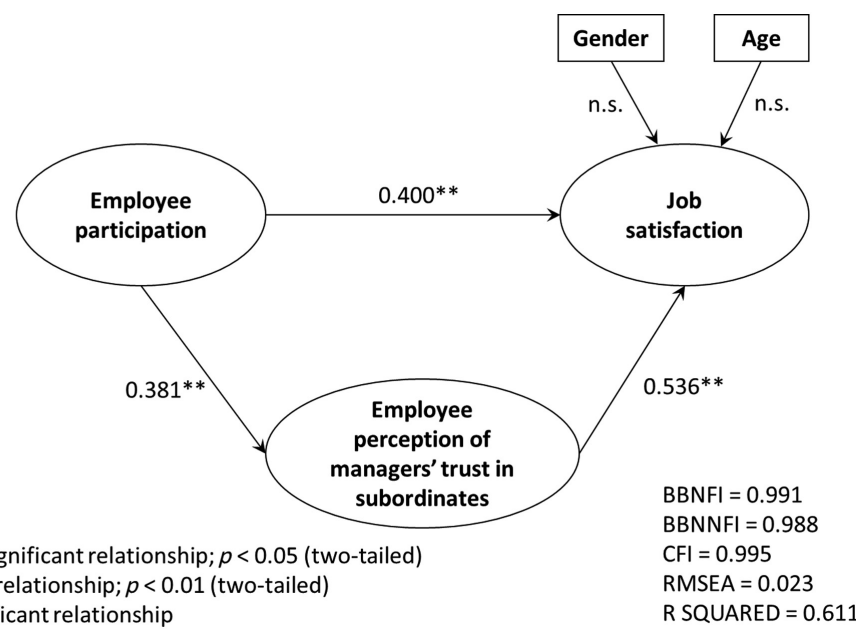

Note(s): * Significant relationship; $p<0.05$ (two-tailed) ** Significant relationship; $p<0.01$ (two-tailed) (n.s.) No significant relationship
$\mathrm{CFI}=0.995$

R SQUARED $=0.611$ 
model explains more of the variance of Job Satisfaction than the direct model; (2) there is a significant relationship between Employee participation and Employee perception of managers' trust in subordinates; (3) the significant relationship between Employee participation and Job satisfaction is lower in the mediation model than in the direct model; and (4) the variables Employee perception of managers' trust in subordinates and Job satisfaction are significantly related.

Figure 3 shows the regression coefficients between the variables and the variance $\left(R^{2}\right)$ in each model. We can conclude that Employee perception of managers' trust in subordinates mediates the relationship between Employee participation and Job satisfaction, because the four requirements mentioned above are met. First, the mediation model explains more of the variance of Job Satisfaction than the direct model (0.611 vs 0.533$)$. Second, the relationship between Employee participation and Employee perception of managers' trust in subordinates is significant (Hypothesis 2: $\beta_{2}=0.381 ; t=10.070 ; p<0.01$ ). Third, the relationship between Employee participation and Job satisfaction is lower in the mediation model $\left(\beta_{1}=0.400\right.$; $t=9.278 ; p<0.01)$ than in the direct model $\left(\beta_{1}=0.730 ; t=19.169 ; p<0.01\right)$. And finally, the variables Employee perception of managers' trust in subordinates and Job satisfaction are significantly related (Hypothesis $3: \beta_{3}=0.536 ; t=8.573 ; p<0.01$ ). Therefore, it can be said that the mediation model is a better fit to reality, thus confirming hypothesis 4 . Additionally, it should be noted that it is a partial mediation, since the direct effect of Employee participation on Job satisfaction remains significant when the mediating variable is included.

\section{Conclusions}

This study reaches two main conclusions from the correlations and results obtained in the regression analyses: first, there is a significant relationship between employee participation and job satisfaction; second, employees' perception that their superiors trust them plays a crucial role in the relationship. For this last reason, the model that includes the mediating variable is a better fit to reality. Scholars of trust consider that it can become a key factor in the management of organizations, and even more so in the technological, constantly changing and complex environment facing companies today (Bachmann and Zaheer, 2006).

Our results show that greater employee involvement leads to a perception that their superiors trust them or, in other words, that managers are willing to take a higher risk with

Direct effect model

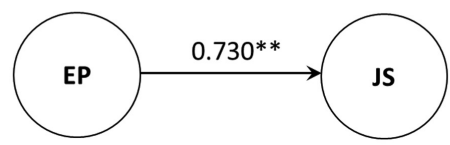

$R^{2}: 0.533$

EP: Employee participation; JS: Job satisfaction
Mediation model

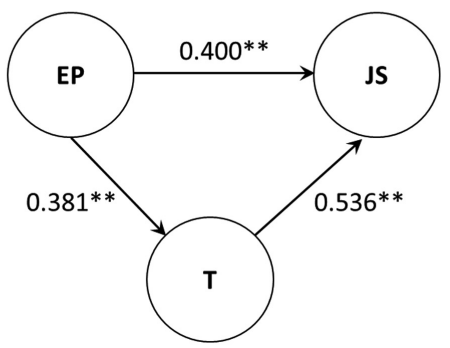

$R^{2}: 0.611$

T: Employee perception of manager's trust in subordinates
Participative decisions and feeling trusted

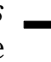


them. This claim is based on the established definitions of trust, according to which, trust derives from high assumption of risk and low risk perception by the trusting party (Mayer et al., 1995). This trust is based on the supervisors' perception that the workers will be able to do their job well, and therefore refers more to the cognitive dimension of trust than to the affective dimension. Thus, when leaders implement participatory decision making, trust increases at the cognitive level.

Furthermore, consistent with previous studies (i.e. Behravesh et al., 2020; Cox et al., 2006), results indicate that the implementation of participation systems involving all workers raises levels of job satisfaction. Our findings add a new alternative way to understand this relationship through the perception of trust, which had not been considered previously. These results lend support to democratic management styles based on a pattern of relationships in which the employee plays a key role in decisions affecting his or her own work, that of colleagues and the functioning of the department and the organization as a whole. Consequently, the worker is no longer simply a cog in the organizational machine, but an essential part of its operations. By empowering workers in this decision-making process and enabling them to influence the future of the company through their decisions, they become agents of change, with the result that they feel more satisfied with their work, as the findings of this study demonstrate.

However, it is important to remember that unless workers have the right skills and preparation to engage with these participatory systems, they may be unable to take on decision making within their area of responsibility on their own. This may ultimately lead to increased job stress and therefore lower job satisfaction. Companies must therefore manage participatory systems properly by first preparing workers to use them and by assigning responsibility in proportion to the position and characteristics of the employee. This entails designing a system that allows employees to make decisions in areas in which they have a minimum of experience and knowledge.

In this study, participation includes consulting with employees to decide the objectives of the work, intervention of employees in processes of the department or the organization and employees having a voice in choosing colleagues. These forms require the employee to be familiar with the operation of the company and the work to be performed, in order to be able to make decisions on a knowledge base. Likewise, although this work focuses on some forms of participation, the participatory culture could be extended to employee involvement in issues such as salary determination, career development or the selection of new employees. This would mean applying a model of direct democracy as proposed by Chiva (2014).

This study has also shown that employees' perception of managers' trust is linked to employee satisfaction. This finding indicates the importance of "feeling trusted". That is, not only do managers trust their employees, but employees perceive that their managers trust them. To the best of our knowledge, this study is the first to address the relationship of this element of trust with job satisfaction. This opens up a line of research with important theoretical and practical implications, since research on vertical trust has, to date, explored ascending trust from employees to their leaders, rather than the consequences of managers' showing trust to their followers. We suggest, therefore, that when managing their relationships with employees, leaders must be able to transmit trust to all levels of the organization.

The results of this study provide evidence of the importance of applying participatory management models in which workers feel trusted. This strategy would allow companies to improve employee satisfaction, and therefore pave the way for employees to show greater commitment and loyalty to their company and to attract and retain talent in organizations. In direct contrast to authoritarian and hierarchical models, our results show that democratic and participative models of business management enable companies to promote a healthier and richer working environment where much more humane and productive working relationships can flourish. 


\subsection{Limitations and future lines of research}

Although our results show positive and significant relationships between the variables examined, we cannot strictly infer the exact causal relationship between them because this was a transversal study. Longitudinal studies are therefore required in order to corroborate the direction of the relationships. Another limitation concerns the way in which the sample data were obtained. Although surveys have certain advantages such as low economic cost, they also have disadvantages such as inflexibility, impersonality and loss of interest on the part of the interviewee. Future research would benefit from including qualitative research, which could provide more valuable answers. Another shortcoming is related to culture and context. The conclusions of this research refer only to the Spanish business model, and according to Rousseau et al. (1998) context is crucial for the implications of trust. This limits to some extent the conclusions obtained and reveals the need for future research in other cultures or countries.

Moreover, the role of culture on the results of employee participation must be also considered. Two dimensions of culture are the main ones to exert an effect on participative decision making (Sagie and Aycan, 2003): power distance and individualism-collectivism. In low power distance cultures, such is the case of western countries like Spain, employees may see themselves as similar to bosses and thus prefer to have a voice in decisions processes (Elele and Fields, 2010). In contrast, individuals from high power distance cultures (such as Asian countries) accept that employees and bosses are unequal and may be less adversely affected by low levels of voice (Brockner and Higgins, 2001). Thus, the relationship between participation and satisfaction could be stronger in cultures with low power distance, as is the case of the one used in this study. Moreover, in more individualistic cultures (such is the case of Spain) participation is mostly relevant to individuals since uniqueness and self-expression are highly valued (Yates and De Oliveiria, 2016). By contrast, individuals in collectivistic cultures pursue participation with the entire group. Hence, in more individualistic cultures individuals may be more comfortable taking decisions alone. So, they feel more satisfied by taking decisions than members of collectivistic cultures who prefer taking decisions in groups. Consequently, the results are contingent on the culture of the study sample. Future studies may compare whether the results can be extrapolated to high power distance and collectivist cultures.

On the other hand, while there is no doubt that the 3,364 respondents are representative of the workforce in Spain, it would be very interesting to find out if results vary according to firm size or business sector. Future research could usefully undertake a comparative analysis considering specific contextual variables. Nonetheless, we believe that our findings provide an overall view of the main effects between the variables examined, which may serve as a starting point for more accurate analysis in future research.

\section{References}

Alas, R. (2007), “The impact of employee participation on job satisfaction during change process", Problems and Perspectives in Management, Vol. 5 No. 4, pp. 28-33.

Altuntas, S. and Baykal, U. (2010), "Relationship between nurses' organizational trust levels and their organizational citizenship behaviors", Journal of Nursing Scholarship, Vol. 42 No. 2, pp. 186-194.

Aziri, B. (2011), "Job satisfaction: a literature review", Management Research and Practice, Vol. 3 No. 4, pp. 77-86.

Bachmann, R. and Zaheer, A. (2006), Handbook of Trust Research, Edward Elgar Publishing, Cheltenham.

Bakker, A.B. and Oerlemans, W. (2011), "Subjective well-being in organizations", in Cameron, K. and Spreitzer, G. (Eds), Handbook of Positive Organizational Scholarship, Oxford University Press, New York, NY, pp. 178-190.
Participative decisions and feeling trusted

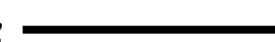


Baptiste, N.R. (2008), "Tightening the link between employee wellbeing at work and performance", Management Decision, Vol. 46 No. 2, pp. 284-309.

Beehr, T.A. (1981), "Work-role stress and attitudes toward co-workers", Group \& Organization Studies, Vol. 6 No. 2, pp. 201-210.

Behravesh, E., Abubakar, A.M. and Tanova, C. (2020), "Participation in decision-making and work outcomes: evidence from a developing economy", Employee Relations, Vol. 43 No. 3, pp. 704-723.

Benoliel, P. and Somech, A. (2010), "Who benefits from participative management?", Journal of Educational Administration, Vol. 48 No. 3, pp. 285-308.

Bhatti, K.K. and Qureshi, T.M. (2007), "Impact of employee participation on job satisfaction, employee commitment and employee productivity", International Review of Business Research Papers, Vol. 3 No. 2, pp. 54-68.

Bingham, S. (2017), "If employees don't trust you, it's up to you to fix it”, Harvard Business Review, available at: https://hbr.org/2017/01/if-employees-dont-trust-you-its-up-to-you-to-fix-it.

Blau, P. (1964), Exchange and Power in Social Life, Wiley, New York.

Braun, S., Peus, C., Weisweiler, S. and Frey, D. (2013), "Transformational leadership, job satisfaction, and team performance: a multilevel mediation model of trust", The Leadership Quarterly, Vol. 24 No. 1, pp. 270-283.

Brockner, J. and Higgins, E.T. (2001), "Regulatory focus theory: implications for the study of emotions at work", Organizational Behavior and Human Decision Processes, Vol. 86 No. 1, pp. 35-66.

Brower, H.H., Lester, S.W., Korsgaard, M.A. and Dineen, B.R. (2009), "A closer look at trust between managers and subordinates: understanding the effects of both trusting and being trusted on subordinate outcomes", Journal of Management, Vol. 35 No. 2, pp. 327-347.

Brower, H.H., Lester, S.W. and Korsgaard, M.A. (2017), "Want your employees to trust you? Show you trust them", Harvard Business Review, available at: https://hbr.org/2017/07/want-youremployees-to-trust-you-show-you-trust-them.

Bruno, R. and Jordan, L. (1999), "From high hopes to disillusionment: the evolution of worker attitudes at Mitsubishi Motors", Advances in Industrial and Labor Relations, Vol. 9, pp. 153-182.

Chiva, R. and Alegre, J. (2009), "Organizational learning capability and job satisfaction: an empirical assessment in the ceramic tile industry", British Journal of Management, Vol. 20 No. 3, pp. 323-340.

Chiva, R. (2014), "The common welfare human resource management system", Personnel Review, Vol. 43 No. 6, pp. 937-956.

Cotton, J.L., Vollrath, D.A., Froggatt, K.L., Lengnick-Hall, M.L. and Jennings, K.R. (1988), "Employee participation: diverse forms and different outcomes", Academy of Management Review, Vol. 13 No. 1, pp. 8-22.

Cox, A., Zagelmeyer, S. and Marchington, M. (2006), "Embedding employee involvement and participation at work", Human Resource Management Journal, Vol. 16 No. 3, pp. 250-267.

Coyle-Shapiro, J.A.M., Morrow, P.C., Richardson, R. and Dunn, S.R. (2002), "Using profit sharing to enhance employee attitudes: a longitudinal examination of the effects on trust and commitment”, Human Resource Management, Vol. 41 No. 4, pp. 423-439.

Crawford, E.R., LePine, J.A. and Rich, B.L. (2010), "Linking job demands and resources to employee engagement and burnout: a theoretical extension and meta-analytic test", Journal of Applied Psychology, Vol. 95 No. 5, p. 834.

Davis, T.R. (2001), "Integrating internal marketing with participative management", Management Decision, Vol. 39 No. 2, pp. 121-132.

Dirks, K.T. and Ferrin, D.L. (2001), "The role of trust in organizational settings", Organization Science, Vol. 12 No. 4, pp. 450-467. 
Elele, J. and Fields, D. (2010), "Participative decision making and organizational commitment: comparing Nigerian and American employees", Cross Cultural Management: International Journal, Vol. 17 No. 4, pp. 368-392.

Gabriel, A.S., Diefendorff, J.M., Chandler, M.M., Moran, C.M. and Greguras, G.J. (2014), "The dynamic relationships of work affect and job satisfaction with perceptions of fit", Personnel Psychology, Vol. 67 No. 2, pp. 389-420.

Ganzach, Y. (1998), "Intelligence and job satisfaction”, Academy of Management Journal, Vol. 41 No. 5, pp. 526-539.

Guest, D.E. (2017), "Human resource management and employee well-being: towards a new analytic framework", Human Resource Management Journal, Vol. 27 No. 1, pp. 22-38.

Guinot, J. and Barghouti, Z. (2019), "The value of trust in employees: discovering its effects on participation and motivation", Business and Society Review, Vol. 16 No. 3, pp. 108-145.

Guinot, J. and Chiva, R. (2019), "Vertical trust within organizations and performance: a systematic review”, Human Resource Development Review, Vol. 18 No. 2, pp. 196-227.

Guinot, J., Chiva, R. and Roca-Puig, V. (2014), "Interpersonal trust, stress and satisfaction at work: an empirical study", Personnel Review, Vol. 43 No. 1, pp. 96-115.

Harrington, M. (2017), "Survey: people's trust has declined in business, media, government, and NGOs", Harvard Business Review, available at: https://hbr.org/2017/01/survey-peoples-trusthas-declined-in-business-media-government-and-ngos.

Huang, W., Li, Y., Wang, S. and Weng, J. (2016), “Can 'democratic management' improve labour relations in market-driven China?”, Asia Pacific Journal of Human Resources, Vol. 54 No. 2, pp. 230-257.

Judge, T.A., Hulin, C.L. and Dalal, R.S. (2012), "Job satisfaction and job affect", in Kozlowski, S.W.J. (Ed), Oxford Library of Psychology. The Oxford Handbook of Organizational Psychology, Oxford University Press, New York, Vol. 1, pp. 496-525.

Judge, T.A., Zhang, S.C. and Glerum, D.R. (2020), “'Job satisfaction”, in Sessa, Valerie I. and Bowling, Nathan A. (Eds), Essentials of Job Attitudes and Other Workplace Psychological Constructs, Routledge, New York, NY, pp. 207-241.

Kalleberg, A.L. and Loscocco, K.A. (1983), "Aging, values, and rewards: explaining age differences in job satisfaction”, American Sociological Review, Vol. 48 No. 1, pp. 78-90.

Kim, S. (2002), "Participative management and job satisfaction: lessons for management leadership", Public Administration Review, Vol. 62 No. 2, pp. 231-241.

Laloux, F. (2014), Reinventing Organizations: A Guide to Creating Organizations Inspired by the Next Stage in Human Consciousness, Nelson Parker, Brussels.

Lau, C.M. and Tan, S.L.C. (2006), "The effects of procedural fairness and interpersonal trust on job tension in budgeting", Management Accounting Research, Vol. 17 No. 2, pp. 171-186.

Lawler, E.J. and Thye, S.R. (1999), "Bringing emotions into social exchange theory", Annual Review of Sociology, Vol. 25 No. 1, pp. 217-244.

Locke, E.A. (1969), "What is job satisfaction?", Organizational Behavior and Human Performance, Vol. 4 No. 4, pp. 309-336.

Matzler, K. and Renzl, B. (2006), "The relationship between interpersonal trust, employee satisfaction and employee loyalty", Total Quality Management and Business Excellence, Vol. 17 No. 10, pp. 1261-1271.

Mayer, R., Davis, J.H. and Schoorman, F.D. (1995), “An integrative model of organizational trust”, Academy of Management Review, Vol. 20 No. 3, pp. 709-734.

Nunnally, J.C. (1978), Psychometric Theory, McGraw-Hill, New York.

Perry, R.W. and Mankin, L.D. (2007), "Organizational trust, trust in the chief executive and work satisfaction”, Public Personnel Management, Vol. 36 No. 2, pp. 165-179. 
Rousseau, D.M., Sitkin, S.B., Burt, R.S. and Camerer, C. (1998), "Not so different after all: a crossdiscipline view of trust", Academy of Management Review, Vol. 23 No. 3, pp. 393-404.

Sagie, A. and Aycan, Z. (2003), "A cross-cultural analysis of participative decision-making in organizations", Human Relations, Vol. 56 No. 4, pp. 453-473.

Salas-Vallina, A., Pozo, M. and Fernandez-Guerrero, R. (2020), "New times for HRM? Well-being oriented management (WOM), harmonious work passion and innovative work behavior", Employee Relations, Vol. 42 No. 3, pp. 561-581.

Shah, D.V. (1998), "Civic engagement, interpersonal trust, and television use: an individual-level assessment of social capital", Political Psychology, Vol. 19 No. 3, pp. 469-496.

Swearingen, M.H. (2017), Participative Management: An Analysis of its Effect on Productivity, Routledge, London.

Tannenbaum, A.S. (1968), Control in Organizations, McGraw-Hill, New York.

Tippins, M.J. and Sohi, R.S. (2003), "IT competency and firm performance: is organizational learning a missing link?", Strategic Management Journal, Vol. 24 No. 8, pp. 745-761.

Tremblay, D.G. (2012), "Work-family balance: is the social economy sector more supportive. . . and is this because of its more democratic management?", Review of Social Economy, Vol. 70 No. 2, pp. 200-232.

Twaronite, K. (2016), "A global survey on the ambiguous state of employee trust", Harvard Business Review, available at: https://hbr.org/2016/07/a-global-survey-on-the-ambiguous-state-ofemployee-trust.

Wagner, J.A. (1994), "Participation's effects on performance and satisfaction: a reconsideration of research evidence", Academy of Management Review, Vol. 19 No. 2, pp. 312-330.

Wanous, J.P., Reichers, A.E. and Hudy, M.J. (1997), "Overall job satisfaction: how good are single-item measures?”, Journal of Applied Psychology, Vol. 82 No. 2, pp. 247-252.

Weinberg, A., Bond, F., Cooper, C. and Sutherland, V.J. (2010), Organizational Stress Management: a Strategic Approach, Palgrave Macmillan, New York, NY.

Wilkinson, A., Gollan, P., Marchington, M. and Lewin, D. (2010), "Conceptualising employee participation in organisations", in Wilkinson, A., Gollan, P., Marchington, M. and Lewin, D. (Eds), The Oxford Handbook of Participation in Organizations, Oxford University Press, Oxford.

Wong, Y.Y., Chow, I.H.S., Lau, V.P. and Gong, Y. (2018), "Benefits of team participative decision making and its potential to affect individual creativity", Journal of Applied Social Psychology, Vol. 48 No. 7, pp. 369-376.

Yates, J.F. and de Oliveira, S. (2016), "Culture and decision making", Organizational Behavior and Human Decision Processes, Vol. 136, pp. 106-118.

Yukl, G.A. and Becker, W.S. (2006), "Effective empowerment in organizations", Organization Management Journal, Vol. 3 No. 3, pp. 210-231.

\section{Further reading}

Bos, J.T., Donders, N.C., Bouwman-Brouwer, K.M. and Van der Gulden, J.W. (2009), "Work characteristics and determinants of job satisfaction in four age groups: university employees' point of view", International Archives of Occupational and Environmental Health, Vol. 82 No. 10, pp. 1249-1259.

Brower, H.H., Schoorman, F.D. and Tan, H.H. (2000), "A model of relational leadership: the integration of trust and leader-member exchange", The Leadership Quarterly, Vol. 11 No. 2, pp. 227-250.

Chen, J.C., Silverthorne, C. and Hung, J.Y. (2006), "Organization communication, job stress, organizational commitment, and job performance of accounting professionals in Taiwan and America”, The Leadership and Organization Development Journal, Vol. 27 No. 4, pp. 242-249. 
Dirks, K.T. and Ferrin, D.L. (2002), "Trust in leadership: meta-analytic findings and implications for research and practice", Journal of Applied Psychology, Vol. 87 No. 4, pp. 611-628.

Erdem, F. and Ozen, J. (2003), "Cognitive and affective dimensions of trust in developing team performance”, Team Performance Management, Vol. 9 Nos 5/6, pp. 131-135.

Eurofound (2015), "Sixth European working conditions survey", [online] available at: https://www. eurofound.europa.eu/es/surveys/european-working-conditions-surveys/sixth-europeanworking-conditions-survey-2015 (accessed 5 April 2020).

Hackman, J.R. and Oldham, G.R. (1975), "Development of the job diagnostic survey", Journal of Applied Psychology, Vol. 60 No. 2, pp. 159-170.

Hackman, J.R. and Oldham, G.R. (1980), Work Redesign, Addison-Wesley, Reading, MA.

Hwang, J.I. and Chang, H. (2008), "Explaining turnover intention in Korean public community hospitals: occupational differences", International Journal of Health Planning and Management, Vol. 23 No. 2, pp. 119-138.

INSST (2015), "Encuesta nacional de Condiciones de Trabajo", [online] available at: https://www.insst. es/-/encuesta-nacional-de-condiciones-de-trabajo-2015-6-ewcs-espa-1 (accessed 10 April 2020).

Judge, T.A., Thoresen, C.J., Bono, J.E. and Patton, G.K. (2001), "The job satisfaction-job performance relationship: a qualitative and quantitative review", Psychological Bulletin, Vol. 127 No. 3, pp. 376-407.

Kraimer, M.L., Seibert, S.E. and Liden, R.C. (1999), "Psychological empowerment as a multidimensional construct: a test of construct validity", Educational and Psychological Measurement, Vol. 59 No. 1, pp. 127-142.

Lewis, J.D. and Weigert, A. (1985), “Trust as a social reality”, Social Forces, Vol. 63 No. 4, pp. 967-985.

Marchington, M. and Wilkinson, A. (2005), "Direct participation and involvement", in Bach, S. (Ed.), Managing Human Resources, Blackwell, Oxford.

Mayer, R.C. and Gavin, M.B. (2005), "Trust in management and performance: who minds the shop while the employees watch the boss?", Academy of Management Journal, Vol. 48 No. 5, pp. 874-888.

McAllister, D.J. (1995), "Affect-and cognition-based trust as foundations for interpersonal cooperation in organizations", Academy of Management Journal, Vol. 38 No. 1, pp. 24-59.

McCauley, D.P. and Kuhnert, K.W. (1992), "A theoretical review and empirical investigation of employee trust in management", Public Administration Quarterly, Vol. 16 No. 2, pp. 265-284.

Pierce, J.L. and Gardner, D.G. (2004), "Self-esteem within the work and organizational context: a review of the organization-based self-esteem literature", Journal of Management, Vol. 30 No. 5, pp. 591-622.

Spreitzer, G.M. and Mishra, A.K. (2002), "To stay or to go: voluntary survivor turnover following an organizational downsizing", Journal of Organizational Behavior, Vol. 23 No. 6, pp. 707-729.

\section{Corresponding author}

Jacob Guinot can be contacted at: guinotj@uji.es

For instructions on how to order reprints of this article, please visit our website:

www.emeraldgrouppublishing.com/licensing/reprints.htm

Or contact us for further details: permissions@emeraldinsight.com 